\section{PERCEPÇÕES DE PROFESSORES SOBRE TRABALHO DOCENTE E REPERCUSSÕES SOBRE SUA SAÚDE}

\section{Teachers' perceptions of teaching work and repercussions on their health}

\author{
Percepciones de profesores sobre el trabajo docente y sus \\ repercusiones en la salud
}

\section{RESUMO}

Objetivo: Analisar as percepções de professores sobre o trabalho docente e as repercussões em sua saúde. Métodos: Estudo de natureza qualitativa constituído por doze docentes da rede estadual de ensino de um município da Bahia-BR. A coleta de dados ocorreu entre os meses de outubro de 2011 e janeiro de 2012, através de grupo focal. Para análise e interpretação dos dados utilizou-se a Técnica de Análise de Conteúdo, emergindo três categorias temáticas: Necessidades de mudança no ambiente de trabalho; Fatores que influenciam na saúde do professor; Consequência do trabalho docente em sua saúde. Resultados: Observa-se que os docentes necessitam de assistência para sua saúde e arco familiar, com políticas públicas visando à prevenção de agravos. Refletem que o trabalho docente apresenta uma alta demanda, aliado à disciplina em sala de aula e desvalorização profissional, que contribuem para o surgimento de distúrbios musculoesqueléticos e emocionais. Múltiplos fatores do trabalho e os hábitos de vida repercutem na saúde docente, modificando sua qualidade de vida. Conclusão: O estudo possibilitou investigar um cenário docente caracterizado pela alta demanda da atividade, aliados a sobrecarga física e mental e desvalorização profissional. O desenvolvimento de estratégias de intervenção e avaliação de sua aplicabilidade é necessário para melhoria da qualidade de vida de professores.

Descritores: Docentes; Saúde do trabalhador; Percepção; Saúde Pública.

\section{ABSTRACT}

Objective: To analyze teachers' perceptions of the teaching work and the repercussions on their health. Methods: Qualitative study conducted with twelve teachers from public schools of a municipality of Bahia. Data were collected between October 2011 and January 2012 using focus group. Data were analyzed and interpreted using the Content Analysis Technique resulting into three thematic categories: Needs for changes in the work environment; Factors influencing the teacher's health; Consequence of the teaching work on their health. Results: It was verified that teachers need assistance for their health and familiar arch with public policies aimed at disease prevention. They reflect that the teaching work is demanding and requires discipline in the classroom but is undervalued, which contributes to the development of musculoskeletal and emotional disorders. Multiple job factors and lifestyle have consequences on teachers' health, changing their quality of life. Conclusion: This study allowed to assess the teaching scenario, characterized by a high demand of activities, physical and mental overload and professional undervaluation. The development of intervention strategies and the evaluation of its applicability are needed to improve teachers' the quality of life.

Descriptors: Faculty; Occupational Health; Perception; Public health.
Artigo Original
1) Universidade Estadual do Sudoeste da Bahia - UESB - Jequié (BA) - Brasil
Recebido em: 28/07/2013 Revisado em: 10/09/2013 Aceito em: 24/11/2013 


\section{RESUMEN}

Objetivo: Analizar las percepciones de profesores sobre el trabajo docente y las repercusiones en su salud. Métodos: Estudio de naturaleza cualitativa constituido de doce docentes de la red estadual de enseñanza de un municipio de Bahí-BR. La recogida de datos se dio entre los meses de octubre de 2011 y enero de 2012 a través de grupo focal. Para el análisis e interpretación de los datos se utilizó de la Técnica de Análisis de Contenido del cual surgió tres categorías temáticas: Necesidades de cambio en el ambiente de trabajo; Factores que influyen en la salud del profesor; Consecuencia del trabajo docente en la salud. Resultados: Se observa que los docentes necesitan asistencia en salud y familiar con políticas públicas para la prevención de enfermedades. Los mismos reflejan que el trabajo docente presenta elevada demanda asociada a la asignatura en clase y desvalorización profesional que contribuyen para la aparición de disturbios muscuesqueleticos y emocionales. Múltiplos factores del trabajo y los hábitos de vida hacen repercutir en la salud del docente cambiando su calidad de vida. Conclusión: El estudio permitió investigar un escenario docente caracterizado por la elevada demanda de actividad asociado a la sobrecarga física y mental y desvalorización profesional. Es necesario el desarrollo de estrategias de intervención y evaluación de su aplicabilidad para la mejoría de la calidad de vida de profesores.

Descriptores: Docentes; Salud Laboral; Percepción; Salud Pública.

\section{INTRODUÇÃO}

Ao longo da história, o trabalho e suas relações com a saúde vêm sendo orientadas a partir das relações socioculturais, econômicas e produtivas, permitindo que esta se diferencie de acordo com a sociedade em que vive. As relações entre saúde e trabalho no ambiente escolar necessitam da compreensão dos trabalhadores em educação dos métodos de organização do trabalho e as condições desencadeantes do processo saúde-doença nestes profissionais. Este conhecimento fornece subsídios para a investigação dos processos do trabalho e as repercussões em saúde, decorrente da interação entre o meio e o indivíduo ${ }^{(1,}$ 2,3).

Observa-se que com o passar do tempo as implementações na organização do trabalho, as alterações do sistema de ensino e a adoção de novas tecnologias, têm gerado diversas transformações no cotidiano do professor ${ }^{(4)}$. Essas mudanças repercutiram profundamente com a elevação da demanda de trabalho desse profissional, que, por sua vez, limitou o tempo deste para atividades como o lazer e os cuidados com a saúde ${ }^{(4,5)}$.

O trabalho docente apresenta condições que englobam esforços físicos, cognitivos e afetivos. Estudos têm demostrado fatores específicos ao exercício dessa profissão como importantes para o desenvolvimento de eventos negativos a sua saúde ${ }^{(5,6,7)}$. A pressão do tempo, desvalorização profissional, dificuldade de contato com colegas e ausência de autonomia são alguns, de muitos fatores, que têm contribuído para o surgimento de doenças e insatisfações, como sintomas de ansiedade, depressão e exaustão emocional ${ }^{(5,6,7)}$.

Estudos realizados no Brasil com intuito de identificar condições de trabalho e de saúde em professores têm contribuído com a identificação de problemas na área da saúde mental, distúrbios musculoesqueléticos e saúde vocal, respectivamente, a síndrome de Burnout, a dor musculoesquelética e a disfonia têm sido veiculadas como importantes problemas da saúde docente ${ }^{(1,2,4,7-9)}$.

A busca de melhores condições de saúde e qualidade de vida do trabalhador docente parte da necessidade de compreender as relações intrínsecas do trabalho, quanto aos fatores estruturais e psicológicos que regem a relação professor-trabalho e, aprofundar o conhecimento a partir das percepções do próprio trabalhador torna-se crucial para fomentar políticas direcionadas.

Assim, objetivou-se analisar as percepções de professores sobre o trabalho docente e as repercussões em sua saúde.

\section{MÉTODOS}

Estudo qualitativo realizado em uma escola da rede estadual de ensino do município de Jequié-BA. A pesquisa qualitativa trata de uma atividade da ciência, que visa à construção da realidade, mas que se preocupa com as ciências sociais em um nível de realidade que não pode ser quantificado, trabalhando com o universo de crenças, valores, significados e outros construtos profundos das relações, que não podem ser reduzidos à operacionalização de variáveis ${ }^{(10)}$.

A rede estadual de ensino neste município possuía, para o ano de 2011, 12 escolas, todas localizadas na zona urbana. Destas 12, escolheu-se aleatoriamente uma para a aplicação do estudo. Como recurso metodológico para coleta de dados, realizou-se grupo focal, caracterizado pela troca de experiências sobre determinado tema, possibilitando a interação entre os participantes e um mediador que provê estímulos ao debate, a fim de favorecer as trocas e descobertas entre os sujeitos ${ }^{(11)}$.

A coleta de dados ocorreu entre os meses de outubro de 2011 e janeiro de 2012. Os encontros aconteceram na sala da coordenação pedagógica da própria escola em dias e horários combinados com a coordenação. No momento do encontro com os docentes, explicaram-se os objetivos 
e a condução do estudo; assim, 12 aceitaram participar do estudo, momento em ocorreu a assinatura do Termo de Consentimento Livre e Esclarecido.

O grupo focal foi composto por um moderador, dois observadores e os sujeitos do estudo, e dois gravadores de voz registravam as discussões ${ }^{(11)}$. $\mathrm{O}$ moderador responsabilizou-se pela condução das atividades através de roteiro pré-estabelecido de perguntas e, os observadores realizaram registros dos aspectos não verbais e a dinâmica da interação entre os docentes. Este roteiro de entrevista continha perguntas relacionadas às expectativas das atividades a serem realizadas na escola, influências do trabalho docente na saúde, conhecimento sobre postura corporal e estilo de vida. Aconteceram dois encontros com intervalos de uma semana, sendo suficientes para realização do presente estudo.

A partir das gravações, fez-se a transcrição das falas e a sua análise, utilizando a Técnica de Análise de Conteúdo ${ }^{(12)}$, seguindo três momentos: no primeiro realizou-se leitura flutuante da transcrição do grupo focal, sendo possível agregar as ideias principais manifestadas nas discussões e os seus significados. Já no segundo momento fez-se a seleção dos núcleos de sentido, através de palavras, frases, parágrafos, trechos que traziam um sentido específico em resposta às questões norteadores do estudo. E, por fim, os núcleos de sentidos passaram por processo de categorização, de acordo com o grau de proximidade e semelhança, determinando-se, portanto, categorias, as quais exprimem significados que proporcionam uma visão diferenciada do tema, sendo estes codificados de maneira a não se perderem na diversidade das mensagens trabalhadas. Assim, emergiram três categorias temáticas: Necessidades de mudança no ambiente de trabalho; Fatores que influenciam na saúde do professor; Consequência do trabalho docente em sua saúde.

Esta pesquisa recebeu aprovação do Comitê de Ética em Pesquisa da Universidade Estadual do Sudoeste da Bahia (CEP/UESB), sob n $n^{\circ}$ 209/2009. Para preservar o anonimato dos participantes, identificaram-se os mesmos de Professores, letra P, seguida de um número cardinal (1, $2,3 \ldots)$.

\section{RESULTADOS E DISCUSSÃO}

A seguir serão apresentadas as categorias temáticas que emergiram do estudo.

\section{Necessidades de mudança no ambiente de trabalho}

A categoria "Necessidade de mudanças no ambiente de trabalho" remeteu ao anseio apresentado pelos professores em relação às modificações no ambiente laboral, visando à manutenção e promoção da saúde docente.
A identificação do ambiente de trabalho como favorecedor de situações negativas ao contexto da saúde do professor pode ser percebida e seguidamente as necessidades de ajuda, a fim de prevenir esses acometimentos, ou seja, os professores demonstram a relevância de adoção de métodos preventivos no ambiente escolar, de maneira que limite e/ ou evite as doenças relacionadas ao trabalho, como os distúrbios vocais, mentais e musculoesqueléticos. Como pode ser visto pelos relatos a seguir:

"Seria interessante se pudesse ser feito um trabalho, se não pode ser feito um trabalho com a voz, mas pelo menos com essas dorzinhas que vão surgindo na gente assim." (P2)

"Voltadas para o bem-estar do funcionário, em beneficio para ele e para familia." (P3)

"Prevenção deveria ter vindo bem antes." (P6)

"Atividades para prevenir, no caso, para não sentir nada." (P8)

Os problemas à saúde do professor têm sido demonstrados em estudos que discutem a preocupação com as condições do ambiente de trabalho dessa categoria profissional ${ }^{(13)}$. Estudo realizado com professores da rede municipal de ensino em Salvador-BA, demonstrou, dentre muitos fatores presentes no ambiente de trabalho, que o ruído excessivo, temperatura, umidade e poeira eram frequentes ${ }^{(14)}$.

Os professores da presente pesquisa demonstraram conhecimento dos problemas de saúde que os afetam e vislumbram a necessidade de estratégias de assistência à saúde para o profissional em seu ambiente de trabalho. Contudo, seriam necessárias políticas públicas e ações de saúde que assegurassem a promoção e a reabilitação, levando em consideração a educação para saúde no ambiente escolar $^{(4)}$. No Distrito Federal do Brasil ${ }^{(15)}$, estratégias para prevenção da saúde vocal de professores de determinada escola foram de fundamental importância na prevenção de agravos à saúde docente. Assim, há necessidade de políticas públicas para a saúde docente com programas de saúde com acompanhamento de profissionais de saúde ${ }^{(16)}$.

\section{Fatores que influenciam na saúde do professor}

Grandes impactos na saúde do professor são advindos das novas políticas educacionais, que modificaram a organização e gestão escolar. A intensificação do trabalho pode comprometer a saúde desses profissionais e a qualidade de ensino, através dos determinantes ambientais e organizacionais ${ }^{(17)}$.

Neste sentido, a categoria "Fatores de interferência na saúde do professor" demonstrou aspectos que interferiram 
no processo saúde-doença, apontando a sobrecarga de trabalho, o cuidado com a própria saúde, a indisciplina escolar de alunos, pressão organizacional da escola, desvalorização profissional e mobiliário inadequado como importantes elementos para produção de eventos adversos à saúde docente. Esses relatos podem ser vistos nos descritos a seguir:

\section{“A carga horária e a quantidade de alunos." (P6)}

"Diante desse contexto social que nós estamos enfrentando, você imagina... você tem cinco horários... você pegou duzentas, imagine... duzentas cabeças diferentes." (P1)

"Tem que tomar um banho ligeiro, muitas vezes você nem relaxa e sai de novo em outra atividade." (P10)

"Não procurei atendimento médico também por que não é nada assim insuportável, mas incomoda." (P1)

“Alguém lembra de se alongar para escrever?... É isso que a gente fala, é isso aí, a gente não tem esse hábito..... Eu mesmo nunca fiz, só fiz uma vez, aqueles exercícios que os fonoaudiólogos ensinaram." (P3,P7)

As falas chamam atenção para os vários aspectos que influenciam no processo saúde-doença do docente. A carga horária docente elevada representa aspecto importante no cotidiano de professores, principalmente no contexto organizacional das atividades desempenhadas, por exemplo, atividades de ensino, leitura, preparação de atividades, entre outras que podem não estar equilibradas para dentro do propósito de tempo institucional/empregatício. Outra condição que leva ao aumento de horas trabalhadas se refere a professores que assumem mais de um vínculo empregatício. Estas situações podem sobrecarregar o desempenho funcional docente e implicar em agravos à saúde ${ }^{(18-20)}$, como mal-estar geral, tonturas, cansaço, esgotamento físico e mental ${ }^{(21)}$.

Em relação aos cuidados com a própria saúde, mais especificamente, relativos aos cuidados no ambiente de trabalho docente, a implementação de estratégias que tenham propósito de continuidade do cuidado pode ser mais eficaz e efetivo. Criar, estimular, praticar e continuar na descoberta por hábitos positivos a saúde pode ser empregado no cotidiano do trabalho docente em consonância as necessidades e particularidades do grupo e do ambiente organizacional da escola, e que essas sejam expressas e desejadas.

Outro aspecto importante, mencionado pelos professores são os ambientes ruidosos, ocasionados pela indisciplina escolar de alunos. As falas em intensidade mais forte e a demanda contínua desse processo podem gerar desgastes nas estruturas de fonação e produzir, com o decorrer do tempo, alterações vocais. Entre tais fatores, podem ser identificados aqueles provindos da falta de informação sobre como produzir a fala com funcionalidade ideal para as diferentes tarefas do ensino, e os hábitos de vida desenvolvidos socioculturalmente ${ }^{(22)}$.

As falas dos professores expressam o cotidiano das salas de aula:

"O aluno não faz silêncio, não prestam atenção aula." (P4)

"Você tem medo de um brigar com o outro e você estar ali no meio, entendeu?" (P12)

"A gente não sabe a reação deles, eles tão muito agressivos." (P12)

Verifica-se que a "indisciplina" no ambiente escolar em geral, constatada pelo comportamento inadequado dos alunos, propicia nos docentes sentimentos de medo, angústia e tensão emocional. As situações vivenciadas na escola podem desencadear alterações físicas e mentais nos professores, existindo associação entre a indisciplina em sala de aula e queixas osteoarticulares e vocais, porque o profissional necessita utilizar de forma intensa a voz e manter-se em pé por períodos prolongados para manter o controle em sala de aula ${ }^{(23)}$.

A pressão sobre a organização da escola e o processo de desvalorização profissional são duas condições que têm sido apontadas por docentes como condições que contribuem negativamente para a manutenção da saúde.

"Eu saio daqui preocupada com as notas da caderneta, não dormi a noite, acordei cinco horas da manhã, comecei a corrigir prova, pra chegar aqui, já passei duas cadernetas." (P3)

"O planejamento do Curso que eu tinha que fechar e entregar a Direção, o prazo já expirou.” (P9)

"Tenta a todo instante a todo o momento descaracterizar o seu trabalho." (P10)

"Final do ano paga uma miséria ao professor.. Considero um desrespeito." (P12)

A pressão organizacional na escola tem contribuído com o desenvolvimento da sobrecarga docente e são promovidos pelo desequilíbrio das demandas do trabalho do professor e o cumprimento dos prazos escolares ${ }^{(6,23)}$. A desvalorização profissional é condição que pode ser bidirecional no sentido de ser fator que contribua na produção do evento adverso à saúde do professor e como resposta às condições enfrentadas na profissão. Nesta última visão, fatores político-administrativos, a exemplo das formas de reconhecimento dos governos com esta classe profissional e a baixa remuneração, são elementos que podem favorecer desfechos negativos à saúde ${ }^{(14,24,25)}$. 
A avaliação dos aspectos ergonômicos no ambiente escolar foi outro fator caracterizado indutor dos problemas de saúde docente.

"Toda hora me vejo assim oh, eu to em pé, eu encosto em uma perna só, coloco o peso todo em uma perna só.” (P1)

"Na hora de escrever, gente,... começo com os movimentos repetitivos." (P3)

"O quadro de giz para quem é baixinha é inadequado... eu só consigo escrever da metade para baixo.” (P8)

"A mesa, a cadeira. Elas lhe induzem a ficar na postura errada..." (P11)

Nas falas, os professores investigados na presente pesquisa enfatizam tanto os aspectos do mobiliário utilizado na escola como os aspectos da postura corporal no desenvolvimento das atividades docentes. Essas condições têm contribuído para desencadear o estresse físico. Enfatiza-se que a manutenção da postura inadequada do educador são propícias para o surgimento de distúrbios musculoesqueléticos ${ }^{(8,9,20)}$.

A exposição a longos períodos em pé ou sentado, aliado ao mobiliário inadequado do estabelecimento de ensino podem comprometer diretamente e intensamente a estrutura osteomuscular e, em segundo nível, acometer a saúde mental ${ }^{(26)}$. Em estudo com professores da rede municipal de ensino de Salvador-BA-BR, foi encontrada associação positiva entre o mobiliário inadequado presente no ambiente escolar com distúrbios musculoesqueléticos em região dorsal ${ }^{(8)}$.

\section{Consequência do trabalho docente em sua saúde}

Permeia pelo ambiente escolar a realidade de vida do professor e as condições e organizações do trabalho docente, as quais repercutem no processo saúde-doença desta categoria ${ }^{(25)}$. Deste modo, a categoria "Consequência do trabalho docente em sua saúde" foi expressada pelos professores contemplando aspectos da tensão emocional provocado pelo trabalho, a privação do lazer e os distúrbios musculoesqueléticos.

"Nós somos submetidos a estresse todos os dias, não é? ... a tensão emocional a que a gente está submetido também." (P5,P8)

“... a escola está na prioridade da nossa vida, está entendendo? e o nosso lazer, onde fica?" (P10)

"Quando eu dou prioridade ao trabalho, ai a minha saúde fica em segundo plano, lazer fica em segundo plano..." (P11)

As falas expressam a tensão no trabalho de docentes que têm sintonia com fatores do trabalho, a exemplo das jornadas prolongadas de trabalho, aumento das demandas do trabalho, percepção da desvalorização profissional, que juntas produzem repercussões psicoemocionais e podem desenvolver nervosismos, tensão emocional e estresse, e exacerbar o desgaste emocional ${ }^{(23)}$.

A organização do trabalho e as condições impostas ao trabalho docente, nos quais o profissional demanda grande parte do seu tempo às atividades escolares, somandose às tarefas domiciliares e ao crescimento profissional, limitam o educador a realizar atividades de lazer. Incluemse nesta situação a dupla jornada de trabalho, que além de hipersolicitar física e mental o trabalhador, limita o tempo de lazer disponível ${ }^{(27)}$, ou seja, as atividades desempenhadas no ambiente laboral docente podem causar alterações no estado como o professor organiza seu tempo, diminuindo assim a disposição para o lazer ${ }^{(17)}$. A privação destas atividades pode ser o fio condutor para o desencadeamento de estresse ${ }^{(7)}$

No curso natural da carreira docente, o professor pode apresentar problemas de origem osteoarticulares, como lombalgia, lesões por esforços repetitivos, dores musculares, as quais são ocasionadas pelas condições de trabalho em que estão submetidos, com alta demanda, mobiliário inadequado e hipersolicitações. As falas dos professores expressam esses problemas da seguinte forma:

"Tenho problemas sérios na cervical que já estão atingindo minha mão." (P2)

"Terminei de corrigir as provas e tive que dormir com os braços enfaixado, para que no outro dia eu pudesse ter mobilidade nos braços, entendeu?"(P9)

"Fico assim, com dor na perna, a perna não para de doer." (P10)

Os problemas osteomusculares são considerados um dos mais expressivos nos estudos sobre saúde do professor. Os indicadores de ocorrência desses eventos apresentam condições de prevalência bastantes elevadas em diferentes localidades de estudo ${ }^{(6,8,9,28,30)}$. A investigação desse evento leva a desdobramentos sobre fatores do trabalho que contribuem com seu desenvolvimento e manutenção, a exemplos dos aspectos organizacionais da escola, os aspectos psicossociais e as demandas físicas enfrentadas por docentes no seu cotidiano.

\section{CONSIDERAÇÕES FINAIS}

O estudo buscou averiguar a partir das percepções de professores as condições de trabalho e condições de saúde dessa classe profissional. Os relatos apresentam um cenário caracterizado pela alta demanda da atividade, aliados à sobrecarga física e mental, e desvalorização profissional. 
As características do trabalho empregado repercutem negativamente no cotidiano desses profissionais, dificultando a realização atividades de lazer e favorecendo o surgimento e/ou manutenção de problemas psicoemocionais e osteomusculares.

Faz-se necessário o desenvolvimento de estratégia de programas de intervenção e prevenção no ambiente de trabalho desses profissionais de forma que assegurem a sua continuidade no cotidiano das escolas. Além disso, estudos de intervenção podem ajudar a entender melhor o uso dessas estratégias no sentido de desequilibrar para eventos positivos a vida de professores.

\section{REFERÊNCIAS}

1. Silvério KCA, Gonçalves CGO, Penteado RZ, Vieira TPG, Libardi A, Rossi D. Ações em saúde vocal: proposta de melhoria do perfil vocal de professores. Pró-Fono Rev Atual Cient. 2008;20(3):177-82.

2. Penteado RZ. Relações entre saúde e trabalho docente: percepções de professores sobre saúde vocal. Rev Soc Bras Fonoaudiol. 2007;12(1):18-22.

3. Rocha KB, Sarriera JC. Saúde percebida em professores universitários: gênero, religião e condições de trabalho. Psicol Esc Educ. 2006;10(2):187-96.

4. Rocha VM, Fernandes MH. Qualidade de vida de professores do ensino fundamental: uma perspectiva para a promoção da saúde do trabalhador. J Bras Psiquiatr. 2008;57(1):23-7.

5. Fontana RT, Pinheiro DA. Condições de saúde autoreferidas de professores de uma universidade regional. Rev Gaúch Enferm. 2010;31(2):270-6.

6. Gasparini SM, Barreto SM, Assunção AA. O professor, as condições de trabalho e os efeitos sobre sua saúde. Educ Pesqui. 2005;31(2):189-99.

7. Reis EJFB, Araújo TM, Carvalho FM, Barbalho L, Silva MO. Docência e exaustão emocional. Educ Soc. 2006;27(94):229-53.

8. Cardoso JP, Ribeiro IQB, Araújo TM, Carvalho FM, Reis EJFB. Prevalência de dor musculoesquelética em professores. Rev Bras Epidemiol. 2009;12(4):604-14.

9. Araújo TM, Carvalho FM. Condições de trabalho docente e saúde na Bahia: estudos epidemiológicos. Educ Soc. 2009;30(107):427-49.

10. Minayo MCS. O desafio do conhecimento: pesquisa qualitativa em saúde. 12ª ed. São Paulo: Hucitec; 2012.

11. Ressel LB, Béck CLC, Gualda DMR, Hoffmann IC, Silva RM, Sehnem GD. O uso do grupo focal em pesquisa qualitativa. Texto \& Contexto Enferm. 2008;17(4):779-86.

12. Bardin L. Análise de conteúdo. Lisboa: Edições 70; 2011.

13. Cruz RM, Lemos JC. Atividade docente, condições de trabalho e processos de saúde. Motricidade. 2005;17(24):59-80.

14. Souza CL, Carvalho FM, Araújo TM, Reis EJFB, Lima VMC, Porto LA. Fatores associados a patologias de pregas vocais em professores. Rev Saúde Pública. 2011;45(5):914-21.

15. Luchesi KF, Mourão LF, Kitamura S, Nakamura HY. Problemas vocais no trabalho: prevenção na pratica docente sob a óptica do professor. Saúde Soc. 2009;18(4):673-81.

16. Lima MFEM, Lima-Filho DO. Condições de trabalho e saúde do/a professor/a universitário/a. Ciênc Cogn. 2009;14(3):62-82.

17. Assunção AA, Oliveira DA. Intensificação do trabalho e saúde dos professores. Educ Soc. 2009;30(107):34972.

18. Araújo TM, Reis EJFB, Carvalho FM, Porto LA, Reis IC, Andrade JM. Fatores associados a alterações vocais em professoras. Cad Saúde Pública. 2008;24(6):122938.

19. Ceballos AGC, Carvalho FM, Araújo TM, REIS EJFB. Avaliação perceptivo-auditiva e fatores associados à alteração vocal em professores. Rev Bras Epidemiol. 2011;14(2):285-95.

20. Delcor NS, Araújo TM, Reis EJFB, Porto LA, Carvalho FM, Silva MO, et al. Condições de trabalho e saúde dos professores da rede particular de ensino de Vitória da Conquista, Bahia, Brasil. Cad Saúde Pública. 2004;20(1):187-96.

21. Gomes L, Brito J. Desafios e possibilidades ao trabalho docente e à sua relação com a saúde. Estud Pesqui Psicol. 2006;6(1):49-62

22. Guidini RF, Bertoncello F, Zanchetta S, Dragone MLS. Correlações Entre Ruído ambiental em sala de aula e voz do Professor. Rev Soc Bras Fonoaudiol. 2012;17(4):398-404.

23. Servilha EAM, Arbach MP. Queixas de saúde em professores universitários e sua relação com fatores de risco presentes na organização do trabalho. Distúrb Comum. 2011;23(2):181-91.

24. Mariano MSS, Muniz HP. Trabalho docente e saúde: o caso dos professores da segunda fase do ensino fundamental. Estud Pesqui Psicol. 2006;6(1):76-88. 
25. Penteado RZ, Pereira IMTB. Qualidade de vida e saúde vocal de professores. Rev Saúde Pública. 2007;41(2):236-43.

26. Provenzano LCFA, Sampaio TMM. Prevalência de disfonia em professores do ensino público estadual afastados de sala de aula. Rev CEFAG. 2010;12(1):97108.

27. Araújo TM, Godinho TM, Reis EJFB, Almeida MMG. Diferenciais de gênero no trabalho docente e repercussões sobre a saúde. Ciênc Saúde Coletiva. 2006;11(4):1117-29.

28. Branco JC, Silva FG, Jansen K, Giusti PH. Prevalência de sintomas osteomusculares em professores de escolas públicas e privadas do ensino fundamental. Fisioter Mov. 2011;24(2):307-14.
29. Mohr PA, Guimarães AV, Barbosa AR. Sintomas de distúrbios osteomusculares em profissionais de educação física, atuantes em academias de Florianópolis-SC. Rev Bras Ciênc Esporte. 2011; 33(4):1041-53.

\section{Endereço para correspondência:}

Thiago Raphael Martins Meira

Universidade Estadual do Sudoeste da Bahia

Departamento de Saúde

Rua José Moreira Sobrinho

Bairro: Jequiezinho

CEP: 45206-190 - Jequié - BA - Brasil

E-mail: jpcardoso@uesb.edu.br 